\title{
Suspensión de terapia dialítica. Análisis de un problema ético-clínico
}

\author{
Silvia Barrios Araya* - Marcela Urrutia Egaña* - Carla Henríquez Henríquez**
}

*Escuela de Enfermería; * Departamento Inmunología Clínica y Reumatología, Escuela de Medicina. Pontificia Universidad Católica de Chile.

\section{Introducción}

Ya desde el antiguo Juramento Hipocrático se hace referencia a la ética en salud, con el conocido primum non nocere. Actualmente, la ética clínica constituye un área clave dentro de las profesiones del área de la salud, esto probablemente dado por el avance de las tecnologías, lo que le ha puesto especial urgencia a la pregunta ética ${ }^{1}$.

Por otro lado, la ética contemporánea se encuentra en una encrucijada por no hallar una salida válida universal a los problemas éticos, ya sea en el campo teórico o en la ética aplicada. Parte del problema es heredado de la época moderna, en que se originaron fracturas en el pensamiento filosófico². Esto cobra vital importancia, pues preguntas éticas a partir de problemas ético-clínicos surgen en el quehacer diario y estas están alejadas de ser fácilmente respondidas. Se define operacionalmente problema ético-clínico como una dificultad en la toma de decisiones frente a una persona (paciente), en cuya resolución es necesario referirse a valores o principios que especifiquen lo que debe ser hecho en oposición a lo que simplemente puede ser hecho o frecuentemente se hace ${ }^{1}$.

Por esto, se ha pensado en contar con un modelo de análisis estructurado que apoye la toma de decisiones en casos de dilemas éticos experimentados en la práctica clínica diaria. Si bien el contexto de un problema

Correspondencia:

sbarrios@uc.cl ético-clínico no permite dar una respuesta concreta, Taboada $^{1}$ propone una metodología que introduce cierta racionalidad en el análisis de los problemas ético-clínicos. Así, el presente artículo tiene por objetivo analizar un problema ético-clínico a través de la aplicación del modelo propuesto por Taboada ${ }^{1}$.

\section{DESCRIPCIÓN DE CASO CLÍNICO}

En un centro de hemodiálisis privado, una enfermera clínica con más de 8 años de experiencia se enfrenta a la situación creada por un hombre de 56 años (pseudónimo: Julio) con diabetes mellitus (DM) desde los 13 años y en tratamiento con hemodiálisis (HD) desde hace 12 años. Es ciego desde hace 10 años y presenta amputación de ambas extremidades. Sus habilidades de comunicación y razonamiento se mantienen intactas.

Julio esta separado y vive en la casa de su sobrina, con ella, su esposo y sus nietos. Él no trabaja, sólo recibe pensión de invalidez. Desde 1995 asiste en forma regular al centro para recibir su terapia con una duración de 4,15 horas 3 veces por semana y requiere traslado en ambulancia hacia el centro de diálisis. El procedimiento en general es mal tolerado, con calambres e hipotensiones moderadas a partir de la tercera hora, náuseas, malestar general e hipoglicemias ocasionales durante los días interdiálisis en los últimos tres años.

Es importante aclarar que dentro de la terapia no se contaba con apoyo psicológico. Un día, solicitó hablar con la enfermera, con tranquilidad para conversar, por lo que se dispuso de tiempo post-terapia de HD para tener una conversación, Julio comunica a la enfermera que no desea seguir asistiendo a la diálisis, porque está cansado de la vida y de sentirse así. Ante 
esto, la enfermera responde que ese día quizás estaba un poco deprimido, sin ánimo, pero que mañana es otro día, amanecerá más contento y las ganas de vivir volverán. Julio tomó su mano y le mencionó que no, pues la verdad es que no volvería al centro de diálisis, por ende lo mejor sería que se despidieran ese día. La enfermera pensó que se trataba de una reacción emocional propia frente al desencanto de su realidad y que pronto se recuperaría. Luego, comunicó la situación al médico de turno y al jefe de servicio y como era habitual, autorizó que fuera llevado a su casa por la ambulancia del centro.

Posteriormente la enfermera se puso en contacto con los familiares de este, quienes confirmaron su decisión de no someterse más a HD y además refirieron un sin número de temores, inquietudes, y por supuesto la tristeza de los resultados de esa decisión. El día en que correspondía una nueva HD, Julio no acudió al centro por lo que, el equipo de salud, compuesto por tres enfermeras, el médico tratante, el médico jefe del centro y el dueño de este quien además era abogado, se reunieron y analizaron la situación de Julio, decidiendo "dejarlo descansar" de una sesión. La enfermera lo llamó por teléfono para darle las indicaciones habituales para una persona que no acude a una HD. Él contestó muy amable, refiriendo "no se preocupen por mi, estoy tranquilo y consciente de mi decisión. No envíen más la ambulancia a buscarme".

A pesar de esto, se envía nuevamente la ambulancia para la siguiente sesión. La enfermera recibe la llamada del chofer informando que Julio no se iba a presentar. La enfermera coordinadora junto al equipo de salud deciden enviar a la fuerza pública a buscarlo, situación que había sido previamente acordada con la sobrina de Julio. Los agentes informaron que hablaron con él, que se negó a acompañarlos y que ellos no podían llevarlo de manera forzada.

Durante los siguientes días, la enfermera llamó a Julio diariamente, intentando apoyar a Julio en la verbalización de sus emociones y pensamientos. La enfermera procuró crear un contacto diario con Julio, en el que se le otorgó apoyo tanto a él como a su familia, para ayudar a "entender la muerte como un acto humano" y por ende, ayudar a morir con dignidad ${ }^{3}$.

Transcurridos 11 días, los familiares de Julio llamaron al centro para informar su fallecimiento, parte del equipo y la enfermera en cuestión asistieron al funeral. Luego, se continuó el soporte telefónico a la familia por una semana tras el fallecimiento de Julio.

\section{Aplicación del modelo de resolución de problemas ético clínicos}

El modelo inicia con la identificación y descripción del problema ético clínico, para esto se plantea una pregunta que tiene por objetivo operacionalizar la descripción, ¿Es moralmente lícito aceptar la decisión de una persona con IRCT de suspender su terapia dialítica? El siguiente paso consiste en identificar los antecedentes de la persona. La tercera etapa es definir los términos involucrados, que son Diabetes Mellitus e Insuficiencia renal crónica terminal (IRCT) que en Chile, es una de las 56 patologías contempladas en el plan de Acceso Universal con Garantías Explicitas en salud (AUGE) del Ministerio de Salud desde el año $2005^{6}$, debido a que se considera una enfermedad de gran impacto en la salud y presupuesto familiar de la población chilena?.

La cuarta etapa consiste en la Identificación de elementos que determinan la moralidad de un acto, para establecer el objeto del acto moral es preciso conocer cuál es la intención de dicho acto y para esto se requiere responder la pregunta ¿qué se está haciendo? (objeto del acto moral). La respuesta debe ir más allá del acto físico, se precisa una descripción que incluya la motivación. Por esto, la pregunta anterior solo muestra una dimensión del acto, entonces, además se exhorta a contestar la pregunta ¿por qué se está haciendo? (fin del acto moral). Estas 2 preguntas intervienen en la calificación de un acto moral, sin embargo no es suficiente, ya que también se debe tomar en cuenta los acontecimientos particulares que rodean el acto (circunstancias del acto moral) $^{1}$.

Es complejo determinar la intencionalidad del acto a través de la descripción de una sola acción, es preciso conocer la motivación que generó dicha acción, y sólo puede ser por medio de la verbalización de lo que es revelado a la conciencia del involucrado. En este caso en particular, la enfermera escuchó atentamente la situación planteada por don Julio, la reacción inicial fue de tratar de convencerlo que era una mala decisión, después informó al médico de turno y a la dirección del establecimiento y se puso en práctica el conducto regular en casos de abandono de la terapia hemodia- 
lítica. Es importante que la motivación de base de la enfermera era hacer el bien, es decir, mantener la vida de la persona, su voluntad se centró en pretender que el continuará su tratamiento pese a la decisión de la persona.

En una segunda lectura, el equipo de salud consideró los acontecimientos, y la enfermera planificó una reunión con el equipo y la familia para informar las acciones futuras. En este punto primó el respeto por parte del equipo de salud al principio de autonomía, es decir, al respeto por la decisión de don Julio. El fin del acto moral tiene como objetivo ordenar los actos del agente, es decir qué se desea obtener. En esta situación la enfermera consideró que ella era responsable de otorgar asistencia emocional a la persona, de informarle de los riesgos de la decisión, de entregar indicaciones sobre restricción hídrica y de la nula ingesta de alimentos ricos en potasio, con el fin de evitar el sufrimiento y acompañarlo durante todo el proceso. Por otro lado, el equipo de salud se reunió con la familia de la persona para informar todas las acciones que el centro de salud tomaría, entre ellas el envío de carabineros en dos oportunidades para tratar de traerlo a su terapia. Es probable que el centro hiciera esto por razones legales como protección en caso de una demanda posterior. Las circunstancias que concurrieron en el caso fueron la intención de la enfermera que afecta de algún modo la bondad de la acción, el cariño con que se dieron las indicaciones y el soporte a la familia.

\section{Referencia a principios de ética clínica involucrados}

En el caso descrito, se puede apreciar que se encontraron en conflicto dos de los principios fundamentales de la bioética: beneficencia y autonomía. Se hace presente el principio de beneficencia, el cuál esgrime el equipo de salud para mantener la vida ${ }^{8}$. Pero ¿qué sucede frente a una persona con su condición de salud basal deteriorada?, ¿se justifica el exceso de tecnología (HD) para prolongar la vida sin considerar la calidad de vida de la misma? Entonces se podría estar frente a un juicio de proporcionalidad terapéutica ${ }^{8}$.

Por otra parte, otro principio ético involucrado es el de autonomía. Al tratarse de una persona consciente, lúcida y orientada en tiempo y espacio, se podría presumir que se trata de una persona competente, sin embargo, para objetivar dicha condición, se requiere de la evaluación de un experto en la materia, que certifique la presencia 0 ausencia de la antes mencionada competencia. Normalmente las personas desean vivir y en este caso es evidente que la decisión de Julio lo llevará a la muerte. Toda decisión que lleve a alguien a la muerte 0 a un daño evidente a sí mismo debe hacer dudar de la competencia, entonces es vital evaluarla más detenidamente.

\section{Análisis de la información clínica éticamente relevante}

Aquí, es importante la certeza diagnóstica. Asimismo, conocer el pronóstico de sobrevida, (la literatura menciona que la curva de supervivencia de las personas que viven con diabetes y que están en HD es de $90 \%$ al año de terapia, $73 \%$ a los 3 años y de $56 \%$ a los 5 años ${ }^{9}$ ). Del mismo modo conocer la competencia de la persona, es difícil determinar esta capacidad, ya que se puede caer en apreciaciones personales ${ }^{8}$. El problema está, como en este caso, cuando las personas ejerciendo su autonomía, rechazan las intervenciones que el personal de salud propone buscando su beneficencia ${ }^{8}$. Por último, identificar la red de apoyo social, desde la perspectiva subjetiva de la valoración de la red de apoyo, Julio vivía en una pieza ubicada atrás de la casa de una sobrina. Él refería que el apoyo en los cuidados para la vida diaria no cumplía sus expectativas. Por otra parte, el apoyo emocional aparentemente si cumplía sus expectativas, pues refería sentirse querido. De igual manera, Julio era beneficiario del sistema de salud pública nacional.

\section{Evaluación de alternativas de acción y sus resultados}

Opción 1: Obligar a la persona a asistir a la terapia con apoyo de la fuerza pública (carabineros). Los beneficios de esta opción serían que el involucrado responda a la presión y asista a diálisis, además esta acción protege al centro de diálisis en caso de demanda. Sin embargo, se debe considerar el costo psicológico de dicha opción al violentar a la persona involucrada y a su familia. Por otra parte, no se respetaría el principio de autonomía de la persona, es decir, la opción estaría centrada en el equipo de salud.

Opción 2: Objetivar la competencia de la persona, para lo que debe ser evaluada por un psiquiatra, quién certificará su estado de salud mental. El principal 
beneficio de esta opción, en caso de que la persona sea calificada como competente, es que la familia y el equipo de salud pueda respetar la decisión de la persona con la certeza de que no hay variables influyentes que intervengan en la toma de decisión (por ejemplo, trastorno del ánimo); para ello la enfermera apoyará la toma de decisión mostrándole los pro y contras de su elección, en conjunto con otras opciones posibles en su caso. Por otra parte, la situación sería diferente si a la persona se le diagnostica un trastorno del ánimo, ya que requeriría tratamiento para ello, el que conlleva un costo económico asociado que no necesariamente es cubierto por el programa GES relacionado con la IRC, ni es asumido por el centro.

Opción 3: No cuestionar la competencia de la persona y aceptar su decisión. Esta situación trae consigo el riesgo de hacer lo incorrecto al no certificar la competencia de la persona, en este caso don Julio, siendo él quien toma la decisión. En las tres opciones antes mencionadas, se debe considerar el apoyo emocional y educacional, a la persona enferma y a su familia.

A continuación sigue la fase de Resolución de Problemas, ésta se centra en la toma de decisiones, por lo cual corresponde hacerse algunas preguntas, tales como, ¿Quién debe decidir?, en este caso si la persona don Julio, es competente, es él quien debe y puede decidir. El equipo de salud le debe proporcionar información para que pueda evaluar y sopesar las consecuencias previsibles de su decisión. Otro cuestionamiento es ¿Qué aspecto de la decisión cae directamente bajo la responsabilidad de enfermería? La enfermera es quien puede sugerir la interconsulta con el psiquiatría al médico tratante y coordinar la reunión con la familia. En esta reunión, la enfermera acordará con los presentes quién asumirá los costos asociados a la decisión tomada, además, será responsable de otorgar el apoyo emocional a la persona (paciente). Por otra parte, debe reunir al equipo de salud para reflexionar en torno al caso, a la decisión tomada y sus consecuencias, para futuras situaciones similares. Por último es requisito evaluar la competencia o capacidad de la persona enferma y/o sus familiares para participar activamente en el proceso de toma de decisiones, ésta idealmente debe ser definida por un psiquiatra.

Implementación practica de la solución, esta última etapa consiste en hacerse 3 preguntas ¿Quién? ¿Cuándo? y ¿Cómo?, la primera corresponde a quien tiene las herramientas para implementar la solución, en este caso es el equipo de salud, liderado por la Enfermera, ¿cuándo se hace? idealmente al momento inmediatamente posterior a detectar el problema.

El análisis crítico de los dilemas ético-clínicos es un aporte relevante para la profesión de enfermería, pues en el quehacer diario se vivencian situaciones de este tipo, en las que se confrontan los distintos principios de bioética, tales como beneficencia y autonomía. EI principio de beneficencia es esgrimido por el equipo de salud, el que está explicitado en el código deontológico de enfermería, publicado por el Consejo Internacional de Enfermeras en el año 200510. Por otra parte, el principio de autonomía es manejado por la persona involucrada, ejerciendo su derecho a autogobernarse ${ }^{11}$.

Sería fundamental que los centros de diálisis cuenten con personal capacitado en el área de la ética y que tuvieran la oportunidad de realizar reuniones clínicas en las que se analicen estos casos, así se podrá lograr un mejor manejo de este tipo de situaciones en beneficio del usuario y su familia. En este caso específico, no se debe obviar la necesidad imperante de una consulta con un psiquiatra para evaluar la competencia del involucrado, situación actualmente no cubierta por el programa GES, por lo que se sugiere considerar la incorporación de una consulta anual al psiquiatra y/o psicólogo a esta garantía.

Este trabajo se ha realizado en el curso Ética, Legislación y Salud, Programa de Magister en Enfermería de la Escuela de Enfermería, Pontificia Universidad Católica de Chile. Profesora Coordinadora: Mg. María Isabel Catoni Salamanca.

\section{Bibliografía}

1. Taboada P. Ética clínica: principios básicos y Modelo de Análisis. Bol Esc Med [Internet]. 1998 [citado 2009 Abr 1]; 27(1), 7-13. Disponible en: http:// escuela.med.puc.cl/paginas/publicaciones/Boletin/ html/Etica/Etica02.html

2. Rodríguez E. Fundamentación antropológica y ontológica de la ética. Ars Med [Intenet]. 2001 [citado 2009 Jun 19]; 5(5). Disponible en: http://escuela. med.puc.cl/publ/ArsMedica/ArsMedica5/Antropologica.html 
3. Taboada P. El derecho a morir con dignidad. Acta Bioeth [Internet]. 2000 [citado 2009 May 4]; 6(1): 89-101. Disponible en: http://www.scielo.cl/pdf/ abioeth/v6nl/art07.pdf

4. Ministerio de Salud (CL). Guías clínica de diabetes meIlitus tipo 1 [Internet]. Santiago: MINSAL; 2005 [citado 2009 Jun 6]. 32 p. Disponible en: http://www.redsalud.gov.cl/archivos/guiasges/DiabetesMellitustipol.pdf

5. Lorenzo SV, Ayus JC, Hernández MD, Torres RA. Manual de nefrología: nefrología clínica, hipertensión arterial, diálisis, transplante renal. 3a ed. Madrid: Elsevier; 2002. 874 p.

6. Fondo Nacional de Salud (CL). ¿Qué es el AUGE? [Internet]. Santiago: FONASA; 2007 [citado 2009 Sep 14]. Disponible en: http://www.fonasa.cl/ prontus_fonasa/antialone.html?page=http://www. fonasa.cl/prontus_fonasa/site/artic/20041129/ pags/20041129111505.html

7. Ministerio de Salud (CL). Guía clínica insuficiencia renal crónica terminal [Internet]. Santiago: MINSAL; 2005 [citado 2009 Ago 29]. 40 p. Disponible en: http://www.minsal.cl/ici/guiasclinicas/INsuficienciaRenal.pdf
8. López R, Nervi F, Taboada P, editores. Manual de medicina paliativa [Internet]. Santiago: Pontificia Universidad Católica de Chile; [2000?]. Análisis de problemas éticos frecuentes; [citado 2009 may 4]; p. 99-123. Disponible en: http://www.cuidadospaliativos.org/archives/medicinafinal.pdf

9. Pérez R, Rodríguez P, Dall'anesse C, Gómez F, Valderrábano $F$. Preocupante incremento de la diabetes como causa de insuficiencia renal terminal: evaluación del tratamiento sustitutivo. An Med Interna [Internet]. 2001 [citado 2009 Jun 10]; 18(4): 175-80. Disponible en: http://scielo.isciii.es/pdf/ami/v18n4/ originall.pdf

10. Consejo Internacional de Enfermeras. Código deontológico del CIE para la profesión de enfermería [Internet]. Ginebra: CIE; c2006 [citado 2009 Jun 26]. 12 p. Disponible en: http://www.icn.ch/ethicsp. $\mathrm{html}$

11. Organización Panamericana de la Salud. Bioética: temas y perspectivas [Internet]. Washington DC: OPS; 1990. Capítulo 2, La relación entre la autonomía y la integridad en la ética médica; [citado 2009 Jun 6]; p. 8-17. Disponible en: http://www. bibliomed.com/biblioteca/paho/bioetica/Cap02.pdf 